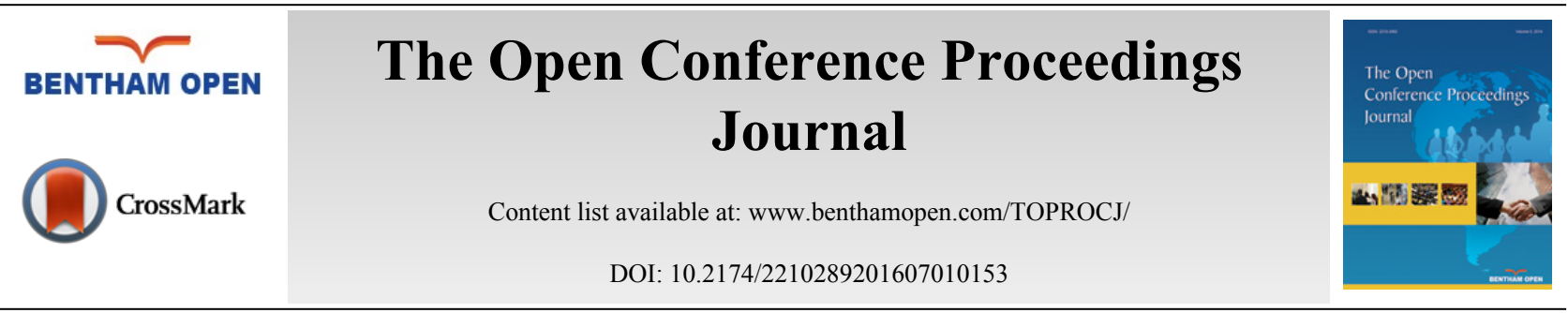

RESEARCH ARTICLE

\title{
Immune Responses to Candidate Vaccine Antigens Delivered Through Naked Plasmid and Mycobacterial Vectors
}

\author{
Abu Salim Mustafa* \\ Department of Microbiology, Faculty of Medicine, Kuwait University, Kuwait, Middle East
}

Received: September 08, 2016

Revised: November 21, 2016

Accepted: November 21, 2016

\begin{abstract}
Tuberculosis (TB) is a major global health problem and has been declared "a global emergency" by the World Health Organization. The failures of the currently available vaccine against TB, i.e. Mycobacterium bovis BCG, to impart consistent protection against TB, have led to the need for alternative vaccines. The low molecular weight major antigenic proteins, i.e. PE35, CFP10 and ESAT6, encoded by Mycobacterium tuberculosis-specific region of difference-1 (RD1) are among the antigens considered important to develop new TB vaccines. To deliver these antigens, two DNA vaccine vectors (pUMVC6 and pUMVC7) and three live mycobacterial species (M. bovis BCG, M. vaccae and M. smegmatis) were evaluated for the induction of antigenspecific cellular immune responses in animals. DNA corresponding to pe35, esat6 and cfp10 genes were amplified using polymerase chain reaction (PCR) from the genomic DNA of M. tuberculosis and cloned into plasmids pUMVC6 and pUMVC7 to prepare DNA vaccine constructs. Furthermore, the PCR-amplified DNA were cloned into a shuttle plasmid (pDE22), and the recombinant shuttle plasmids (pDE22-PE35, pDE22-CFP10 and pDE22-ESAT6) were electroporated into mycobacteria. The induction of antigen specific cellular immune responses was studied by immunizing mice and guinea-pigs with the recombinant constructs. The results with all the recombinant constructs and both animal models showed the consistent induction of antigen-specific cellular immune responses (spleen cell proliferation and secretion of protective $\mathrm{T}$ helper 1 cytokine interferon- $\gamma$ in mice, and delayed-type hypersensitivity skin responses in guinea-pigs) only with the recombinant constructs expressing PE35 protein. These results suggest the superiority of PE35 antigen in inducing protective cellular immune responses in animals.
\end{abstract}

Keywords: Immune responses, Mycobacterial vectors, Plasmid vectors, Tuberculosis, Vaccine.

\section{INTRODUCTION}

The cellular mediated immunity (CMI), primarily mediated by $\mathrm{T}$ cells plays a major role in the protection against and pathogenesis of tuberculosis (TB) [1]. The CMI is dependent upon the interaction of T cells and antigen presenting cells (mostly macrophages and dendritic cells), leading to the differentiation of $\mathrm{T}$ cells into various subclasses, e.g. $\mathrm{T}$ helper (Th)1, Th2 and T regulatory (Treg) cells, etc., which mediate specific functions by secreting effector molecules known as cytokines [2]. Th1 cells stimulate delayed-type hypersensitivity skin reactions and produce cytokines interleukin (IL)-2 and interferon-gamma (IFN- $\gamma$ ), which mediate cellular proliferation and protection against intracellular pathogens, respectively [3]. Th2 cells classically produce cytokines like IL-4 and IL-5, which down regulate Th1 responses, and mediate protection against extracellular pathogens [4]. Treg cells secrete IL-10 and transforming growth factor (TGF)- $\beta$, which are anti-inflammatory cytokines and are involved in regulating and suppressing Th1 and Th2 responses, including inflammation [1].

In TB, Th1 cytokines IL-2 and IFN- $\gamma$ are protective, while Th2 cytokines IL- 4 and IL-5 are associated with the lack of protection [5 - 7]. The Treg cytokine IL-10 is associated with deactivation of macrophages and downregulates the production and nullifies the effect of the protective Th1 cytokine IFN- $\gamma$ [8]. In addition, the ratio of Th1:Th2 and Th1: Treg cytokines is very important in the protection against TB because the protection is better if the ratio is biased towards Th1 cytokines $[9,10]$. Hence, the new vaccine candidates should preferentially induce the protective Th1 cells

\footnotetext{
* Address correspondence to this author at the Department of Microbiology, Faculty of Medicine, Kuwait University, Kuwait, Middle East; Tel: +965-24636505; E-mail: abusalim@hsc.edu.kw
} 
but not Th2 and Treg cells [11 - 13].

The availability of the complete genome sequence of $M$. tuberculosis and its comparison with $M$. bovis BCG strains, currently used for vaccination against TB in the world, had identified several genomic regions of differences (RDs), which are present in M. tuberculosis but deleted/absent in M. bovis BCG [14 - 17]. In particular, three low-molecular weight proteins encoded by the genes present in RD1 locus of $M$. tuberculosis have been identified as the major inducers of Th1-type cellular immune response in humans [18 - 21]. In order to be used as vaccines against TB, these proteins must be delivered through appropriate delivery systems. In this study, PE35, ESAT-6 and CFP10 were evaluated for induction of protective cellular immune responses using recombinant DNA plasmids and recombinant mycobacteria as systems for antigen delivery.

\section{MATERIALS AND METHODOLOGY}

The recombinant plasmid DNA vaccine constructs (nacked plasmids) were generated by cloning PCR-amplified genomic DNA of $M$. tuberculosis corresponding to the pe35, esat6 and cfp10 genes into the two mammalian expression vectors, i.e. pUMVC6 and pUMVC7, as described previously [22]. The recombinant (r)pUMVC6 and rpUMVC7 were propagated in Escherichia coli to obtain large quantities of plasmids for immunization purposes. The plasmids were purified and the presence of the cloned genes in the purified recombinant plasmids were confirmed by polymerase chain reaction (PCR) and DNA sequencing [22]. The recombined plasmids were used to immunize mice and the induction of antigen-specific immune responses was assessed by using spleenocytes in cell proliferation assays using overlapping synthetic peptides corresponding to each protein i.e. PE35, ESAT-6 and CFP10 (Fig. 1), the number of peptides and their amino acid sequences are shown for PE35, according to standard procedures [23]. For cytokine estimations, spleenocytes were re-stimulated in vitro with the peptide pool of PE35 and its individual peptides, and the culture supernatants were tested for the concentration of IFN- $\gamma$, IL-5 and IL-10 using enzyme-linked immunosorbent assays [24].

Peptide no. Amino acid sequence

$\begin{array}{lr}1 & 1 \text {-MEKMSHDPIAADIGTQVSDNALHGV-25 } \\ 2 & 16 \text {-QVSDNALHGVTAGSTALTSVTGLVP-40 } \\ 3 & 31 \text {-ALTSVTGLVPAGADEVSAQAATAFT-5 } \\ 4 & \text { 46-VSAQAATAFTSEGIQLLASNASAQD-70 } \\ 5 & \text { 61-LLASNASAQDQLHRAGEAVQDVART-85 } \\ 6 & \text { 76-GEAVQDVARTYSQIDDGAAGVFAE - } 99\end{array}$

Fig. (1). Peptide nos. (1-6) and amino acid sequences of PE35 peptides.

The overlapping regions of the neighboring peptides are marked in bold.

The recombinant plasmids capable of transforming mycobacteria were generated by PCR-amplification of pe35, esat-6 and cfp10 genes from the genomic DNA of M. tuberculosis and cloning into shuttle plasmid pDE22 [24]. The recombinant plasmids (pDE22-PE35, pDE22-ESAT-6 and pDE22-CFP10) were propagated in E. coli and purified to obtain sufficient quantities to transform mycobacteria. The presence of each $M$. tuberculosis-specific gene in the respective purified recombinant plasmids was confirmed by DNA sequencing [24].

The recombinant pDE22 plasmids were electroporated into wild-type $M$. bovis BCG to generate three strains of recombinant (r)BCG, i.e. rBCG-pDE22-PE35, rBCG-pDE22-ESAT-6 and rBCG-pDE22-CFP10 [24]. Separate groups of mice were immunized with these strains of rBCG and, after appropriate time intervals, spleenocytes were isolated from the immunized mice to study antigen specific cellular immune responses (cellular proliferation, and secretion of IFN- $\gamma$, IL-5 and IL-10) [24].

The recombinant PDE22-PE35 plasmids were also electroporated into wild-type M. vaccae and M. smegmatis [25, 26]. The presence of pe 35 gene in rM. vaccae and $r M$. smegmatis was determined by PCR using gene-specific primers, and the expression of the protein in rM. smegmatis was confirmed by western immunoblotting [25, 26]. Mice were immunized with rM. vaccae and rM. smegmatis, and spleenocytes were isolated to test for PE35-specfic immune responses using cellular proliferation assays [25, 26]. Furthermore, guinea pigs were immunized with rM. smegmatis 
and the induction of Th1-type cellular immune responses were studied by intradermal injection of the peptide-pool and individual peptides of PE35, followed by the measurement of the delayed type hypersensitivity (DTH) skin responses using standard procedures [26].

\section{RESULTS AND DISCUSSION}

In case of DNA vaccine constructs, plasmids pUMVC6 and pUMVC7 were used as the DNA vaccine vectors capable of expressing the cloned genes in mammalian cells [22]. Both of these vectors have the same cytomegalovirus (CMV) promoter at the $5^{\prime}$ end of the cloning site, but they differ in the immunostimulatory fusion peptide that is attached to express the antigenic protein as a recombinant fusion protein. In pUMCV6, the fusion peptide is human interleukin-2 (hIL-2) secretory protein and in pUMCV7 it is the tissue plasminogen activator (tPA) signal peptide [27].

The immunization of mice with all the rpUMCV6 and rpUMCV7, containing pe35, esat6 and cfp10 genes, led to the induction of antigen-specific cellular immunity [23]. However, rpUMCV6 constructs induced relatively stronger responses than rpUMCV7 [23]. The improved responses with rpUMCV6 suggests that hIL2 secretory protein acted as a better adjuvant and enhanced immune responses to the fused mycobacterial proteins more effectively than the tPA signal peptide present in rpUMCV7. Hence, for efficient and appropriate antigen delivery, pUMCV6 would be a better naked plasmid delivery system than pUMCV7.

Because of the improved cellular immune responses, rpUMCV6-PE35 was further evaluated for induction of the protective Th1 responses, and pathologic Th2 and T-reg responses by quantification of IFN- $\gamma$, IL-5 and IL-10, respectively. The results showed that immunization of mice with rpUMCV6-PE35 induced only Th1 responses (as indicated by IFN- $\gamma$ secretion and lack of secretion of IL-5 and IL-10) from spleenocytes of mice in response to PE35 protein [27]. Furthermore, experiments with individual peptides demonstrated that multiple epitopes of PE35 were involved in inducing the Th1 responses (Table 1).

Table 1. Antigen-induced proliferation responses of spleenocytes obtained from mice pre-immunized with rpUMCV6-PE35 and re-stimulated with the peptide pool and individual peptides of PE35.

\begin{tabular}{|c|c|c|}
\hline \multirow{2}{*}{ Peptides of PE35 used for re-stimulation of spleenocytes } & \multicolumn{2}{|c|}{ Mice immunized with } \\
\hline & pUMCV6 & rpUMCV6-PE35 \\
\hline & $\mathrm{P} / \mathrm{T}^{1}$ & $\mathrm{P} / \mathrm{T}^{1}$ \\
\hline Peptide pool of PE35 & $0 / 5$ & $5 / 5$ \\
\hline \multicolumn{3}{|l|}{ Individual peptides of PE35: } \\
\hline 1 & $0 / 5$ & $4 / 5$ \\
\hline 2 & $0 / 5$ & $0 / 5$ \\
\hline 3 & $0 / 5$ & $4 / 5$ \\
\hline 4 & $0 / 5$ & $4 / 5$ \\
\hline 5 & $0 / 5$ & $2 / 5$ \\
\hline 6 & $0 / 5$ & $0 / 5$ \\
\hline
\end{tabular}

${ }^{1}$ No. of mice showing positive responses / the no. of mice tested.

The currently licensed anti-TB vaccine for human use is the live Mycobacterium bovis Bacillus Calmette Guerin (BCG), an attenuated organism produced by extensive in vitro sub-culturing of the pathogenic M. bovis on artificial media [28]. This vaccine has been used to prevent TB since 1921, but it has failed to impact the global problem of tuberculosis [29]. Although, immunization with BCG provides significant protection against severe forms of TB in adults, it has failed to provide consistent protection against the pulmonary diseases in adults, which accounts for about $85 \%$ TB cases [28]. Therefore, there is a need to improve BCG, preferably by using $M$. tuberculosis-specific antigens absent in $M$. bovis BCG [30,31]. Hence, the genes for M. tuberculosis-specific antigens ESAT-6, CFP10 and PE35 were cloned in the shuttle plasmid pDE22, which is capable of expressing the cloned genes in mycobacteria [24], and the recombinant plasmids were electroporated into BCG to generate rBCGs. The various strains of rBCGs, thus generated, were used to study the induction of antigen-specific Th1, Th2 and Treg responses upon immunization of different groups of mice.

The results showed that spleen cells from all groups of mice failed to secrete Th2 cytokine IL-5 in response to the immunizing antigens, whereas Treg cytokine IL-10 was secreted in response to the peptide pools of all three proteins from mice immunized with the respective strains of rBCGs [24]. This suggested the expression of the cloned genes in 
rBCGs and in vivo priming of spleen cells to the expressed proteins, in immunized mice. However, in Th1-cell assays that correlate with protective cellular immune responses, i.e., antigen induced cellular proliferation and IFN- $\gamma$ secretion, only mice immunized with rBCG-pDE22-PE35 yielded positive responses to the peptides of PE35 in both assays [24]. Furthermore, at least two and four epitopes of PE35 were recognized in proliferation and IFN- $\gamma$ secretion assays, respectively (Table 2). In case of rBCG-pDE22-CFP10 and rBCG-pDE22-ESAT-6, only spleen cells from mice immunized with rBCG-pDE22-CFP10 showed positive responses to multiple epitopes of CFP10 in antigen-induced cell proliferation assays, but the animals of both groups lacked antigen-specific secretion of the Th1 cytokine IFN- $\gamma$ [24]. Because the induction of IFN- $\gamma$ responses were limited to rBCG-pDE22-PE35, only the recombinant plasmid pDE22PE35 was considered worthy of further studies in the other two mycobacterial species, i.e. M. vaccae and M. smegmatis.

Table 2. IFN- $\gamma$ concentration $(\mathrm{pg} / \mathrm{ml})$ in culture supernatants of spleenocytes obtained from mice pre-immunized with the BCG and rBCG-pDE22-PE35 and re-stimulated with the peptide pool and individual peptides of PE35.

\begin{tabular}{|c|c|c|}
\hline \multirow{2}{*}{ Peptides of PE35 used for re-stimulation of spleenocytes } & \multicolumn{2}{|c|}{ Mice immunized with } \\
\hline & BCG & rBCG-pDE-PE35 \\
\hline Peptide pool of PE35 & 31 & 201 \\
\hline \multicolumn{3}{|l|}{ Individual peptides of PE35: } \\
\hline 1 & 13 & 110 \\
\hline 2 & $<5.3$ & 61 \\
\hline 3 & 21 & 124 \\
\hline 4 & $<5.3$ & 116 \\
\hline 5 & $<5.3$ & 124 \\
\hline 6 & $<5.3$ & 7.0 \\
\hline
\end{tabular}

The concentration of IFN- $\gamma>100 \mathrm{pg} / \mathrm{ml}$ was considered significant and such values are given in bold.

M. vaccae and M. smegmatis are non-pathogenic environmental mycobacteria and have been employed in TBresearch related to the development of new TB vaccines [32 - 37]. To determine immune responses to specific antigens cloned in $M$. vaccae and M. smegmatis, the rPDE22-PE35 plasmids were also electroporated into M. vaccae and $M$. smegmatis to generate $\mathrm{r} M$. Vaccae and $\mathrm{r}$. smegmatis, respectively. The results in mice immunized with $\mathrm{r} M$. vaccaepDE22-PE35 and rM. smegmatis-pDE22-PE35 showed that multiple peptides of PE35 were recognized by spleenocytes in antigen-induced proliferation assays, i.e. peptides 1, 3, 4 and 5 in mice immunized with rM. vaccae-pDE22-PE35 [25], and peptides 1, 2, 3, 4 and 5 in mice immunized with rM. smegmatis-pDE22-PE35 (Table 3). In guinea-pigs immunized with rM. smegmatis-pDE22-PE35, the same peptide pool of PE35 and its individual peptides induced the DTH skin responses (Table 3). Thus, like mice, guinea-pigs also showed broader responses to multiple epitopes of PE35. The presence of multiple epitopes in PE35 was demonstrated by HLA-DR binding prediction analysis in humans as well (Fig. 2).

Table 3. Antigen-induced proliferation of spleenocytes and DTH responses in mice and guinea-pigs, respectively, preimmunized with rM. smegmatis-pDE22-PE35 and re-stimulated with the peptide pool and individual peptides of PE35.

\begin{tabular}{|c|c|c|}
\hline \multirow{2}{*}{ Peptides of PE35 used for re-stimulation of spleenocytes } & \multicolumn{2}{|c|}{ Animals immunized } \\
\cline { 2 - 3 } & \multicolumn{2}{|c|}{ Guinea-pigs } \\
\hline \multicolumn{2}{|c|}{$\mathbf{P}^{\mathbf{1}}$} \\
\hline Peptide pool of PE35 & Not done & \multicolumn{1}{|c|}{$4 / 4$} \\
\hline Individual peptides of PE35: & $1 / 5$ & $2 / 4$ \\
\hline 1 & $1 / 5$ & $3 / 4$ \\
\hline 2 & $3 / 5$ & $2 / 4$ \\
\hline 3 & $2 / 5$ & $3 / 4$ \\
\hline 4 & $2 / 5$ & $3 / 4$ \\
\hline 5 & $0 / 5$ & $0 / 4$ \\
\hline 6 & & \\
\hline
\end{tabular}

${ }^{1}$ No. of animals showing positive responses / the no. of animals tested. 


Pept
1
2
3
4
5
6

Sequence

$$
\begin{aligned}
& \text { 1-MEKMSHDPIAADIGTQVSDNALHGV-25 } \\
& 16 \text {-QVSDNALHGVTAGSTALTSVTGLVP-40 } \\
& \text { 31-ALTSVTGLVPAGADEVSAQAATAFT-55 } \\
& \text { 46-VSAQAATAFTSEGIQLLASNASAQD-70 } \\
& \text { 61-LLASNASAQDQLHRAGEAVQDVART-85 } \\
& \text { 76-GEAVQDVARTYSQIDDGAAGVFAE -99 }
\end{aligned}
$$

\section{HLA-DR binding $^{\mathrm{a}}$}
$0 / 51$
$0 / 51$
$2 / 51$
$43 / 51$
$1 / 51$
$0 / 51$

Fig. (2). HLA-DR binding predictions for PE35 peptides to 51 HLA-DR alleles. The sequences predicted to bind the HLA-DR alleles are given in bold.

${ }^{a}$ No. of HLA-DR alleles predicted to bind/total no. of HLA-DR alleles analyzed by the ProPred program [38 - 40]

To determine the pathogenesis of rM. smegmatis-pDE22-PE35 construct, experiments were carried out in guineapigs by determining the clearance of rM. smegmatis from internal organs, i.e. liver, lungs and spleen. For comparison purposes another group of guinea-pigs was injected with wild M. smegmatis. The results showed that the rM. smegmatis was cleared from the internal organs, at least, as fast as wild-type M. smegmatis, i.e. within five days [26]. Thus, rM. smegmatis-pDE22-PE35 did not show extended survival in the injected animals.

\section{CONCLUSION}

The results with recombinant DNA vaccine plasmids in mice and recombinant mycobacteria in mice and guineapigs demonstrate that PE35 antigen consistently induced protective Th1-type immune responses in animal models of TB. Furthermore, one of the recombinant constructs (rM. Smegmatis) tested for pathogenesis was found safe. These results suggest that the various constructs of PE35 should be tested in animals for protection against experimental TB, before embarking on human trials.

\section{CONFLICT OF INTEREST}

The author confirms that this article content has no conflict of interest.

\section{ACKNOWLEDGEMENTS}

The work was supported by the College of Graduate Studies and Research Sector, Kuwait University, grant numbers YM01/03, YM12/07, YM14/08, YM15/08 and SRUL02/13.

\section{REFERENCES}

[1] McGuirk, P.; Higgins, S.C.; Mills, K.H. Regulatory cells and the control of respiratory infection. Curr. Allergy Asthma Rep., 2005, 5(1), 51-55.

[http://dx.doi.org/10.1007/s11882-005-0054-4] [PMID: 15659263]

[2] Akdis, M.; Akdis, C.A. Mechanisms of allergen-specific immunotherapy: multiple suppressor factors at work in immune tolerance to allergens. J. Allergy Clin. Immunol., 2014, 133(3), 621-631.

[http://dx.doi.org/10.1016/j.jaci.2013.12.1088] [PMID: 24581429]

[3] Andersen, P.; Woodworth, J.S. Tuberculosis vaccines-rethinking the current paradigm. Trends Immunol., 2014, 35(8), 387-395. [http://dx.doi.org/10.1016/j.it.2014.04.006] [PMID: 24875637]

[4] Zhu, J.; Paul, W.E. Peripheral CD4+ T-cell differentiation regulated by networks of cytokines and transcription factors. Immunol. Rev., 2010, $238(1), 247-262$.

[http://dx.doi.org/10.1111/j.1600-065X.2010.00951.x] [PMID: 20969597]

[5] Mustafa, A.S.; Al-Attiyah, R. Mycobacterium tuberculosis antigens and peptides as new vaccine candidates and immunodiagnostic reagents against tuberculosis. Kuwait Med. J., 2004, 36, 171-176.

[6] Mustafa, A.S.; Skeiky, Y.A.; Al-Attiyah, R.; Alderson, M.R.; Hewinson, R.G.; Vordermeier, H.M. Immunogenicity of Mycobacterium tuberculosis antigens in Mycobacterium bovis BCG-vaccinated and M. bovis-infected cattle. Infect. Immun., 2006, 74(8), 4566-4572. [http://dx.doi.org/10.1128/IAI.01660-05] [PMID: 16861643]

[7] Mustafa, A.S. T-helper 1, T-helper 2, pro-inflammatory and anti-inflammatory cytokines in tuberculosis. IJPMB, 2014, 3, 1-14.

[8] Al-Attiyah, R.; Mustafa, A.S. Characterization of human cellular immune responses to novel Mycobacterium tuberculosis antigens encoded by genomic regions absent in Mycobacterium bovis BCG. Infect. Immun., 2008, 76(9), 4190-4198. 
[http://dx.doi.org/10.1128/IAI.00199-08] [PMID: 18573897]

[9] Redford, P.S.; Boonstra, A.; Read, S.; Pitt, J.; Graham, C.; Stavropoulos, E.; Bancroft, G.J.; OGarra, A. Enhanced protection to Mycobacterium tuberculosis infection in IL-10-deficient mice is accompanied by early and enhanced Th1 responses in the lung. Eur. J. Immunol., 2010, 40(8), 2200-2210. [http://dx.doi.org/10.1002/eji.201040433] [PMID: 20518032]

[10] Mustafa, A.S.; Al-Saidi, F.; El-Shamy, A.S.; Al-Attiyah, R. Cytokines in response to proteins predicted in genomic regions of difference of Mycobacterium tuberculosis. Microbiol. Immunol., 2011, 55(4), 267-278. [http://dx.doi.org/10.1111/j.1348-0421.2011.00307.x] [PMID: 21244466]

[11] Mustafa, A.S. Characterization of a cross-reactive, immunodominant and HLA-promiscuous epitope of Mycobacterium tuberculosis-specific major antigenic protein PPE68. PLoS One, 2014, 9(8), e103679.

[http://dx.doi.org/10.1371/journal.pone.0103679] [PMID: 25136958]

[12] Mustafa, A.S. Recombinant and synthetic peptides to identify Mycobacterium tuberculosis antigens and epitopes of diagnostic and vaccine relevance. Tuberculosis (Edinb.), 2005, 85(5-6), 367-376. [Edinb]. [http://dx.doi.org/10.1016/j.tube.2005.08.006] [PMID: 16253561]

[13] Mustafa, A.S. Mycobacterial gene cloning and expression, comparative genomics, bioinformatics and proteomics in relation to the development of new vaccines and diagnostic reagents. Med. Princ. Pract., 2005, 14(Suppl. 1), 27-34. [http://dx.doi.org/10.1159/000086182] [PMID: 16103711]

[14] Cole, S.T.; Brosch, R.; Parkhill, J.; Garnier, T.; Churcher, C.; Harris, D.; Gordon, SV.; Eiglmeier, K.; Gas, S.; Barry, C. E., 3rd; Tekaia, F.; Badcock, K.; Basham, D.; Brown, D.; Chillingworth, T.; Connor, R.; Davies, R.; Devlin, K.; Feltwell, T.; Gentles, S.; Hamlin, N.; Holroyd, S.; Hornsby, T.; Jagels, K.; Krogh, A.; McLean, J.; Moule, S.; Murphy, L.; Oliver, K.; Osborne, J.; Quail, MA.; Rajandream, MA.; Rogers, J.; Rutter, S.; Seeger, K.; Skelton, J.; Squares, R.; Squares, S.; Sulston, JE.; Taylor, K.; Whitehead, S.; Barrell, BG. Deciphering the biology of Mycobacterium tuberculosis from the complete genome sequence. Nature, 1998, 393(6685), 537-544.

[15] Behr, M.A.; Wilson, M.A.; Gill, W.P.; Salamon, H.; Schoolnik, G.K.; Rane, S.; Small, P.M. Comparative genomics of BCG vaccines by whole-genome DNA microarray. Science, 1999, 284(5419), 1520-1523. [http://dx.doi.org/10.1126/science.284.5419.1520] [PMID: 10348738]

[16] Mustafa, A.S. Biotechnology in the development of new vaccines and diagnostic reagents against tuberculosis. Current Pharm. Biotechnol, 2001, 2(2), 157-173.

[http://dx.doi.org/10.2174/1389201013378707]

[17] Mustafa, A.S. Development of new vaccines and diagnostic reagents against tuberculosis. Mol. Immunol., 2002, 39(1-2), 113-119. [http://dx.doi.org/10.1016/S0161-5890(02)00048-2] [PMID: 12213334]

[18] Mustafa, A.S.; Amoudy, H.A.; Wiker, H.G.; Abal, A.T.; Ravn, P.; Oftung, F.; Andersen, P. Comparison of antigen-specific T-cell responses of tuberculosis patients using complex or single antigens of Mycobacterium tuberculosis. Scand. J. Immunol., 1998, 48(5), 535-543. [http://dx.doi.org/10.1046/j.1365-3083.1998.00419.x] [PMID: 9822264]

[19] Berthet, F.X.; Rasmussen, P.B.; Rosenkrands, I.; Andersen, P.; Gicquel, B. A Mycobacterium tuberculosis operon encoding ESAT-6 and a novel low-molecular-mass culture filtrate protein (CFP-10). Microbiology, 1998, 144(Pt 11), 3195-3203. [http://dx.doi.org/10.1099/00221287-144-11-3195] [PMID: 9846755]

[20] Hanif, S.N.; El-Shammy, A.M.; Al-Attiyah, R.; Mustafa, A.S. Whole blood assays to identify Th1 cell antigens and peptides encoded by Mycobacterium tuberculosis-specific RD1 genes. Med. Princ. Pract., 2008, 17(3), 244-249. [http://dx.doi.org/10.1159/000117800] [PMID: 18408395]

[21] Mustafa, A.S.; Al-Attiyah, R.; Hanif, S.N.; Shaban, F.A. Efficient testing of large pools of Mycobacterium tuberculosis RD1 peptides and identification of major antigens and immunodominant peptides recognized by human Th1 cells. Clin. Vaccine Immunol., 2008, 15(6), 916-924.

[http://dx.doi.org/10.1128/CVI.00056-08] [PMID: 18400977]

[22] Hanif, S.N.M; Mustafa, A.S. TB DNA vaccines; review and advances. In: Vaccines \& Vaccine Technologies, Jose Ronnie Vasconcelos, Ed.; OMICS Group International: Foster City, 2015, Chapter 5, pp. 1-7.

[23] Hanif, S.N.M; Al-Attiyah, R.; Mustafa, A.S. DNA vaccine constructs expressing Mycobacterium tuberculosis-specific genes induce immune responses. Scand. J. Immunol., 2010, 72(5), 408-415.

[http://dx.doi.org/10.1111/j.1365-3083.2010.02452.x] [PMID: 21039735]

[24] Shaban, K.; Amoudy, H.A.; Mustafa, A.S. Cellular immune responses to recombinant Mycobacterium bovis BCG constructs expressing major antigens of region of difference 1 of Mycobacterium tuberculosis. Clin. Vaccine Immunol., 2013, 20(8), 1230-1237. [http://dx.doi.org/10.1128/CVI.00090-12] [PMID: 23761657]

[25] Amoudy, H.A.; Ebrahimi, B.H.; Mustafa, A.S. Immune responses against Mycobacterium tuberculosis-specific proteins PE35 and CFP10 in mice immunized with recombinant Mycobacterium vaccae. Saudi Med. J., 2014, 35(4), 350-359. [PMID: 24749131]

[26] Al-Mutairi, S.K. Immunogenicity and pathogenesis of RD1 region proteins expressed in Mycobacterium smegmatis and Mycobacterium bovis BCG. MSc Thesis, Kuwait University; Kuwait, April 2011.

[27] Hanif, S.N.M; Al-Attiyah, R.; Mustafa, A.S. Cellular immune responses in mice induced by M. tuberculosis PE35-DNA vaccine construct. Scand. J. Immunol., 2011, 74(6), 554-560. 
[http://dx.doi.org/10.1111/j.1365-3083.2011.02604.x] [PMID: 21812801]

[28] Mustafa, A.S.; Al-Attiyah, R. Tuberculosis: looking beyond BCG vaccines. J. Postgrad. Med., 2003, 49(2), $134-140$. [PMID: 12867689]

[29] Mustafa, A.S. Vaccine potential of Mycobacterium tuberculosis-specific genomic regions: in vitro studies in humans. Expert Rev. Vaccines, 2009, 8(10), 1309-1312. [http://dx.doi.org/10.1586/erv.09.93] [PMID: 19803751]

[30] Mustafa, A.S. Diagnostic and vaccine potentials of ESAT-6 family proteins encoded by M. tuberculosis genomic regions absent in M. bovis BCG. J. Mycobac. Dis., 2013, 3, 129.

[http://dx.doi.org/10.4172/2161-1068.1000129]

[31] Mustafa, A.S. Whats new in the development of tuberculosis vaccines. Med. Princ. Pract., 2012, 21(3), $195-196$. [http://dx.doi.org/10.1159/000337919] [PMID: 22488019]

[32] Ahsan, M.J.; Garg, S.K.; Vashistha, B.; Sharma, P. Tuberculosis vaccines: hopes and hurdles. Infect. Disord. Drug Targets, 2013, 13(5), 318-321.

[http://dx.doi.org/10.2174/1871526513666131201125513] [PMID: 24304353]

[33] Gröschel, M.I.; Prabowo, S.A.; Cardona, P.J.; Stanford, J.L.; van der Werf, T.S. Therapeutic vaccines for tuberculosisa systematic review. Vaccine, 2014, 32(26), 3162-3168. [http://dx.doi.org/10.1016/j.vaccine.2014.03.047] [PMID: 24726245]

[34] Faludi, I.; Szabó, A.M.; Burián, K.; Endrész, V.; Miczák, A. Recombinant Mycobacterium smegmatis vaccine candidates. Acta Microbiol. Immunol. Hung., 2011, 58(1), 13-22.

[http://dx.doi.org/10.1556/AMicr.58.2011.1.2] [PMID: 21450551]

[35] Tsolaki, A.G.; Nagy, J.; Leiva, S.; Kishore, U.; Rosenkrands, I.; Robertson, B.D. Mycobacterium tuberculosis antigen 85B and ESAT-6 expressed as a recombinant fusion protein in Mycobacterium smegmatis elicits cell-mediated immune response in a murine vaccination model. Mol. Immunol., 2013, 54(3-4), 278-283.

[http://dx.doi.org/10.1016/j.molimm.2012.11.014] [PMID: 23333882]

[36] Junqueira-Kipnis, A.P.; de Oliveira, F.M.; Trentini, M.M.; Tiwari, S.; Chen, B.; Resende, D.P.; Silva, B.D.; Chen, M.; Tesfa, L.; Jacobs, W.R., Jr; Kipnis, A. Prime-boost with Mycobacterium smegmatis recombinant vaccine improves protection in mice infected with Mycobacterium tuberculosis. PLoS One, 2013, 8(11), e78639. [http://dx.doi.org/10.1371/journal.pone.0078639] [PMID: 24250805]

[37] Alves Da Silva, D.; Cavalcanti, M.A.; Muniz De Oliveira, F.; Trentini, M.M.; Junqueira-Kipnis, A.P.; Kipnis, A. Immunogenicity of a recombinant Mycobacterium smegmatis vaccine expressing the fusion protein CMX in cattle from Goiás State, Brazil. J. Vet. Med. Sci., 2014, 76(7), 977-984.

[http://dx.doi.org/10.1292/jvms.13-0338] [PMID: 24681608]

[38] Mustafa, A.S. Th1 cell reactivity and HLA-DR binding prediction for promiscuous recognition of MPT63 (Rv1926c), a major secreted protein of Mycobacterium tuberculosis. Scand. J. Immunol., 2009, 69(3), 213-222. [http://dx.doi.org/10.1111/j.1365-3083.2008.02221.x] [PMID: 19281533]

[39] Al-Attiyah, R.; Mustafa, A.S. Computer-assisted prediction of HLA-DR binding and experimental analysis for human promiscuous Th1-cell peptides in the $24 \mathrm{kDa}$ secreted lipoprotein (LppX) of Mycobacterium tuberculosis. Scand. J. Immunol., 2004, 59(1), 16-24. [http://dx.doi.org/10.1111/j.0300-9475.2004.01349.x] [PMID: 14723617]

[40] Mustafa, A.S. In silico analysis and experimental validation of Mycobacterium tuberculosis -specific proteins and peptides of Mycobacterium tuberculosis for immunological diagnosis and vaccine development. Med. Princ. Pract., 2013, 22(Suppl. 1), 43-51. [http://dx.doi.org/10.1159/000354206] [PMID: 24008694]

(C) Abu Salim Mustafa; Licensee Bentham Open

This is an open access article licensed under the terms of the Creative Commons Attribution-Non-Commercial 4.0 International Public License (CC BY-NC 4.0) (https://creativecommons.org/licenses/by-nc/4.0/legalcode), which permits unrestricted, non-commercial use, distribution and reproduction in any medium, provided the work is properly cited. 